\title{
The Level and Role of Interleukin-17 in Patients of Type 2 Diabetes Mellitus with and without Complications
}

\author{
Ashirbad Parhi ${ }^{*}$, Sidhartha Das ${ }^{2}$, Srikrushna Mahapatra ${ }^{3}$, Nikhilesh Pradhan ${ }^{2}$, \\ Manoranjan Behera2 ${ }^{2}$, Bijan Patnaik ${ }^{2}$, Roma Rattan ${ }^{3}$ \\ ${ }^{1}$ Department of Cardiology, SCBMCH, Cuttack, India \\ ${ }^{2}$ Department of Medicine, SCBMCH, Cuttack, India \\ ${ }^{3}$ Department of Biochemistry, SCBMCH, Cuttack, India \\ Email: *parhiashirbad@gmail.com
}

How to cite this paper: Parhi, A., Das, S., Mahapatra, S., Pradhan, N., Behera, M., Patnaik, B. and Rattan, R. (2019) The Level and Role of Interleukin-17 in Patients of Type 2 Diabetes Mellitus with and without Complications. Journal of Diabetes Mellitus, 9, 176-185.

https://doi.org/10.4236/jdm.2019.94017

Received: May 29, 2019

Accepted: November 25, 2019

Published: November 28, 2019

Copyright $\odot 2019$ by author(s) and Scientific Research Publishing Inc. This work is licensed under the Creative Commons Attribution International License (CC BY 4.0).

http://creativecommons.org/licenses/by/4.0/

\begin{abstract}
Background: Type 2 Diabetes Mellitus (T2DM) is the most prevalent metabolic disorder in the world. Recent evidence however suggests that T2DM is not only a disease of metabolism, but also an inflammatory disorder and that inflammation also plays an important role in the pathogenesis of Diabetic complications. Our aim was to study the level of interleukin-17 (IL 17) in Indian populations with T2DM as an inflammatory marker and analyze its role in different diabetic complications. Methods: A total of consecutive 67 patients of T2DM were evaluated for clinical parameters fasting blood glucose (FBG), 2hr-post-prandial blood glucose (PPBG), lipid profile, HbAlc and plasma IL 17. They were divided into three groups-Patients of T2DM without any complications (group A; $\mathrm{n}=24$ ), T2DM with acute complications (group $\mathrm{B} ; \mathrm{n}=20$ ), T2DM with chronic complications (group $\mathrm{C} ; \mathrm{n}=23$ ) and compared with 23 healthy controls (group D). Results: Diabetic patients had a higher level of IL 17 as compared to the healthy controls. The level of IL 17 in complicated diabetics was higher than the patients with T2DM without complications. Multiple logistic regression analysis showed positive correlation of IL 17 with Diabetic Retinopathy and Diabetic Neuropathy. IL 17 also showed a positive Pearsons correlation with systolic blood pressure (SBP), diastolic blood pressure (DBP), serum triglycerides (TG), serum total cholesterol (TC), very low density lipoproteins (VLDL), low density lipoproteins (LDL), HbAlc and a negative correlation with HDL. Conclusion: Indian subjects with T2DM with or without complications had higher values of IL 17 as compared to healthy controls. Also diabetic neuropathy and diabetic retinopathy were positively correlated to levels of IL 17. Further levels of IL 17 were positively correlated to hypertension and dyslipidemia indicating a preva-
\end{abstract}


lent inflammatory state in our population of T2DM with and without complications.

\section{Keywords}

IL-17, Inflammation, Interleukins

\section{Introduction}

Diabetes Mellitus is a heterogenous chronic metabolic disorder principally characterised by persistent hyperglycemia resulting from defects in insulin secretion, action or both. Recent studies have shown that diabetes is a proinflammatory state [1]. The studies reveal an increased levels of highly sensitive $\mathrm{C}$ reactive protein (hs CRP), toll like receptors 2 (TLR 2), TLR 4 and plasminogen activator inhibitor-1 (PAI-1), soluble adhesion molecules, sCD 40 and proinflammatory cytokines interleukin-1 $\beta$ (IL $1 \beta$ ), IL 6 , and tumour necrosis factors (TNF- $\alpha$ ) in diabetics. Gene profiling has suggested that high glucose exposure to monocytes leads to increased expression of pro-inflammatory cytokines, chemokines and related factors, many of which are regulated by the pro-inflammatory transcription factor nuclear factor $\kappa$-B (NF- $\kappa$ B $)$ [2]. In addition to that, Adiponectin, which is anti-inflammatory in nature, is also found to be lower in patients of diabetes mellitus [3]. Its level is also found to be lower in patients of diabetes mellitus with macrovascular and microvascular complications. Diabetes as a proinflammatory state has also been established in our population by Das et al. [4].

Recent studies, suggest that adaptive immune system, especially $\mathrm{T}$ lymphocyte, also plays a pivotal role in the pathogenesis of T2DM. One particular type of T lymphocytes named Th17, which is a subset of $\mathrm{T}$ helper cells produces IL 17. Recently there has been increasing evidence of the proinflammatory interleukin 17 (IL 17) playing an important role in patients of diabetes mellitus and its complications [5]. IL-17A activates the JAK1, JAK2, PI3K and NF- $\kappa$ B pathways which up-regulate inflammatory gene expression [6]. It also activates MAPK, CEBP cascade which increases proinflammatory gene expression of cytokines like TNF $\alpha$, IL1, IL6, G-CSF, and MMP which mediate tissue infiltration and destruction. Also recent study described ongoing $\beta$-cell destruction by IL1b and TNF $\alpha$ [7]. Also there have been studies regarding increased levels of IL 17 in vitreous humour, and increased Th 17 cells in the renal tissues indicating significant role of IL 17 in the complication of diabetes [8]. Literature in India regarding the role of interleukin 17 in patients of T2DM with and without complications is sparse. Therefore, we decided to evaluate the role of IL 17 in patients of diabetes mellitus with and without complications in our population.

\section{Materials and Methods}

It was a hospital based observational study conducted in the Post Graduate De- 
partment of Medicine and Biochemistry S.C.B Medical College, Cuttack. Study period was from August 2017-November 2017. The target population constituted of 67 consecutive Type 2 DM patients admitted to Post Graduate Department of Medicine, S.C.B Medical College, Cuttack from August 2017 to November 2017 were enrolled for the study. The study group was divided into four groups-Group A consisted of patients of T2DM without any complications $(\mathrm{N}=24)$, Group B consisted of patients with acute complications $(\mathrm{N}=20)$, Group C constituted patients with chronic complications $(\mathrm{N}=23)$. Healthy controls were put in Group $\mathrm{D}$ $(n=23)$. Because of financial constraints, we could afford only 1 kit for IL-17 estimation (PicoKine ELISA Kit) which has 96 wells. 6 of the wells were used up for determination of the standard curve and the rest was used for our patients, hence the sample size of 90 patients which were divided into 4 groups.

All Type 2 DM patients of both gender of age group more than $30 \mathrm{yr}$, attending out-patient department or admitted in our wards were included in the study. Patients with Type 1 Diabetes, Gestational Diabetes, Secondary Diabetes, known cases of connective tissue disorder and infections were excluded from the study.

DM was diagnosed according to WHO criteria. Blood glucose estimation was done by glucose oxidase method in venous blood. Glycosylated haemoglobin (HbA1c) estimation was done by ion exchange chromatography method. Blood glucose level estimation was done by glucose oxidase method using a standard kit supplied by Acutex Biochemical Pvt Ltd. Lipid profile, liver function tests (LFT), serum urea, creatinine and electrolytes done by autoanalyzer (TBA120 FR, TOSHIBA) using specific kits. Serum total cholesterol (TC) was estimated using Enzokit supplied by Ranbaxy fine chemicals limited. Triglycerides (TG) was estimated using standard kit by Chemelex SA, Barcelona. Low density lipoprotein (LDL) was estimated using standard kit supplied by Agappe diagnostics ltd. High density lipoprotein (HDL) was estimated using a standard kit supplied by Trans Asia Biochemicals. Very low density lipoproteins (VLDL) was estimated by dividing TG/5.

Acute complications of T2DM include hyperglycemic hyperosmolar state (HHS), diabetic ketoacidosis (DKA) and hypoglycaemia. Chronic complications of diabetes include microvascular complications: diabetic nephropathy, diabetic neuropathy and retinopathy as well as macrovascular complications: cerebrovascular accident (CVA), coronary artery disease (CAD) and peripheral artery disease (PAD).

Estimation of IL 17: IL 17 was calculated using 1L 17 PicoKine ELISA Kit manufactured by Boster Biological Technology Co., Ltd. (Catalog no-EKO430) Size-96 wells/kit. It was a Sandwich ELISA kit for Quantitative detection of human IL-17 in cell culture supernates, cell lysates. tissue homogenates, serum and plasma (heparin, EDTA. Sample was kept at $-20^{\circ} \mathrm{C}$ after proper dilution by diluents buffer.

\section{Preparation and Storage of the Sample}

Plasma was collected using EDTA as the anticoagulant. It was centrifuged for 15 
minutes at $1500 \times \mathrm{g}$ within 30 minutes of collection. The sample was stored at -20 degree centigrade. The sample was then diluted with a proper dilution factor and the diluted target concentration was achieved near the middle of the linear regimen in the standard curve. The dilution was done using provided diluents. The samples and standards were added and incubated at $37^{\circ} \mathrm{C}$. The biotynated antibody was added and incubated at $37^{\circ} \mathrm{C}$ for 60 minutes. The plate was washed three times with $0.001 \mathrm{M}$ TBS solution, then $0.1 \mathrm{ml}$ solution of the $\mathrm{ABC}$ solution was added to each well and sealed with an adhesive cover and incubated at $37^{\circ} \mathrm{C}$ for 30 minutes. Then the plate was washed 5 times with $0.01 \mathrm{~m}$ TBS of each twice. The washing buffer was to stay in the wells for 1 to 2 minutes. 90 micro litre of prepared TMB colour developing agents was added to each wells and sealed with a new adhesive cover and incubated at $37^{\circ} \mathrm{C}$ in the dark for $15-20$ minutes. $0.1 \mathrm{ml}$ of prepared TMB was added to each to each well. The colour changes into yellow immediately. The optical density absorbance at $450 \mathrm{~nm}$ was read in a microplate reader within 30 minutes after adding the stock solution. Human IL-17 concentration of samples was calculated from the standard curves. Statistical analysis was done using SPSS statistical package version 21.0. Quantitative variables were described as mean \pm standard deviation (SD) unless otherwise indicated qualitative variables were described by percentage. Multiple logistic regression analysis with stepwise additions of variables was performed to assess their association with each of the complication studied. For all statistical tests, $\mathrm{P}$ value $<0.05$ was considered significant.

\section{Observation}

The demographic characteristics, blood pressure values of group A, B, C and D comparing the mean difference between groups are shown in Table 1.

Table 2 shows the mean values of different biochemical parameters in the form of FBG, 2 Hr PPBG, Urea, Creatinine.

Table 3 shows comparison of plasma level of IL17 (in pg/ml) in different groups (normal value $<10 \mathrm{pg} / \mathrm{ml}$ ). The highest level of IL-17 is seen in diabetics with chronic complications (group C) with a mean value of $39.727 \pm 9.96 \mathrm{pg} / \mathrm{ml}$. The second highest level is seen in DM with acute complications (group B) with a mean level of $20.3865 \pm 6.78761 \mathrm{pg} / \mathrm{ml}$. The mean value of serum IL-17 for control group (group D) is within normal limits.

Table 3 also shows the mean levels of IL 17 in males and females among different groups. The mean level of IL 17 of females in each group was more than that of male group. But the control group shows that the mean level is more in case of males as compared to females.

Table 4 shows the multivariate regression analysis showing association of age, HbA1c, TC, BMI, SBP, IL17, Serum Creatinine with Diabetic Retinopathy. Among these, IL17 showed statistically significant association with retinopathy (P-value of 0.017).

Table 5 shows multivariate regression analysis showing association of age, 
duration, HBA1c, BMI, IL17, SBP, Serum Creatinine with Diabetic Neuropathy. Diabetic neuropathy shows significant association with IL17 ( $p$-value of 0.033 ).

Pearson's correlation (Table 6) of IL 17 with Age, Duration, HbA1c, TC, TG, HDL, LDL, VLDL, BMI, SBP, DBP, FBG, 2 Hr PPBG shows that IL 17 has a statistically significant positive correlation with values of $\mathrm{HBA} 1 \mathrm{c}$, duration of disease, TC, TG, VLDL, LDL, SBP, DBP, 2 HrPPBG. It has got a statistically significant negative correlation with $\mathrm{HDL}(\mathrm{r}=-0.289$; $\mathrm{P}$ value $=0.006)$.

Table 1. Demographic characteristics, blood pressure values of groups.

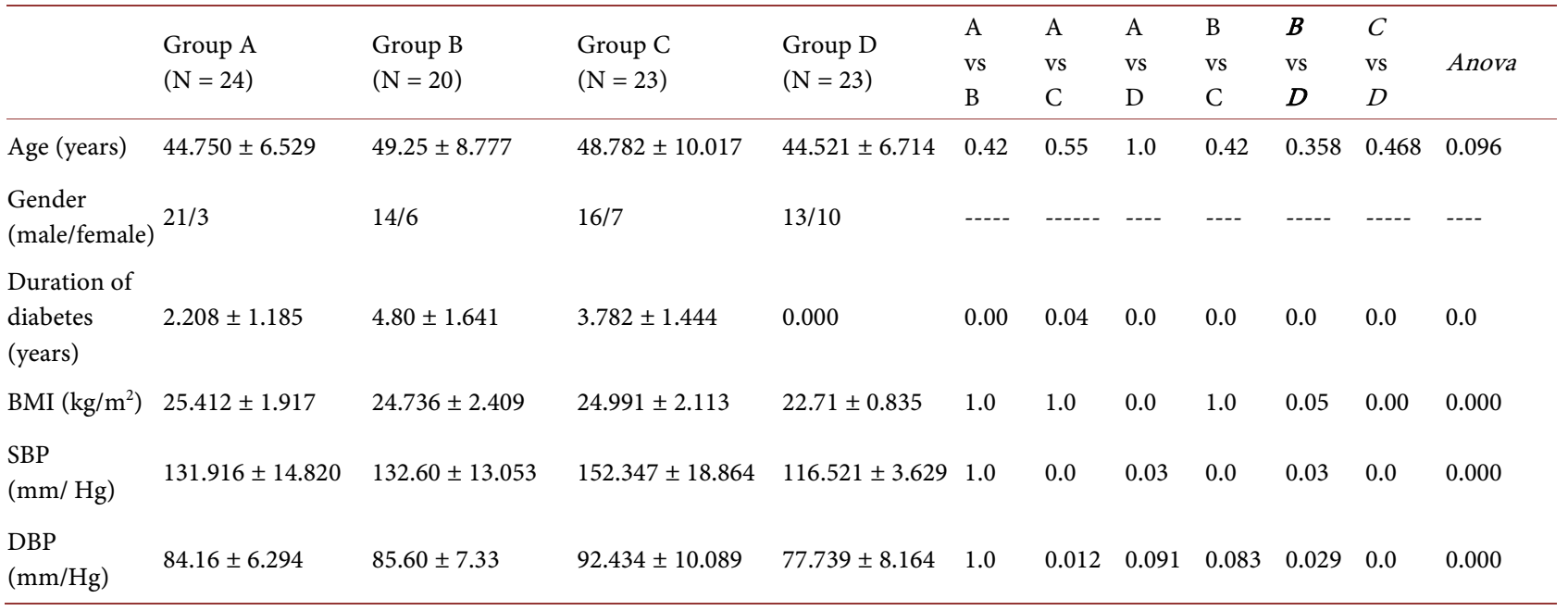

Table 2. Biochemical properties of groups.

\begin{tabular}{|c|c|c|c|c|c|}
\hline & Group A & Group B & Group C & Group D & ANOVA \\
\hline $\begin{array}{c}\text { FBG } \\
(\mathrm{mg} / \mathrm{dl})\end{array}$ & $135.875 \pm 10.385$ & $454.400 \pm 29.331$ & $141.173 \pm 22.738$ & $84.217 \pm 6.954$ & 0.000 \\
\hline $2 \mathrm{Hr}$ PPBG (mg/dl) & $229.250 \pm 20.128$ & $526.550 \pm 30.576$ & $242.130 \pm 45.518$ & $123.521 \pm 5.500$ & 0.000 \\
\hline $\begin{array}{c}\text { HbAlc } \\
(\%)\end{array}$ & $7.258 \pm 0.620$ & $8.975 \pm 1.733$ & $8.147 \pm 1.105$ & $5.343 \pm 0.233$ & 0.000 \\
\hline $\begin{array}{l}\text { Sr. Urea } \\
\text { (mg/dl }\end{array}$ & $26.125 \pm 5.277$ & $43.500 \pm 9.746$ & $58.208 \pm 14.350$ & $24.347 \pm 5.415$ & 0.000 \\
\hline $\begin{array}{l}\text { Sr. Creat } \\
(\mathrm{mg} / \mathrm{dl})\end{array}$ & $0.879 \pm 0.184$ & $1.240 \pm 0.287$ & $3.278 \pm 1.250$ & $0.717 \pm 0.166$ & 0.000 \\
\hline
\end{tabular}

Table 3. Mean levels of Il 17 in different groups and its distribution in males and females between different groups.

\begin{tabular}{|c|c|c|c|c|}
\hline & Male & Female & Total & $\mathrm{P}$ value \\
\hline Group A & $\begin{array}{c}13.295 \pm 3.145 \\
\quad(\mathrm{~N}=21)\end{array}$ & $\begin{array}{c}13.4 \pm 2.047 \\
\quad(\mathrm{~N}=3)\end{array}$ & $\begin{array}{c}13.3213 \pm 2.867 \\
(\mathrm{~N}=24)\end{array}$ & $>0.05$ \\
\hline Group B & $\begin{array}{c}19.6266 \pm 6.535 \\
(\mathrm{~N}=14)\end{array}$ & $\begin{array}{c}22.666 \pm 7.78955 \\
(N=6)\end{array}$ & $\begin{array}{c}20.3865 \pm 6.787 \\
(\mathrm{~N}=20)\end{array}$ & $<0.001$ \\
\hline Group C & $\begin{array}{c}38.96 \pm 10.949 \\
(\mathrm{~N}=16)\end{array}$ & $\begin{array}{c}41.90 \pm 6.770 \\
(\mathrm{~N}=7)\end{array}$ & $\begin{array}{c}39.727 \pm 9.967 \\
(\mathrm{~N}=23)\end{array}$ & $>0.05$ \\
\hline Group D & $\begin{array}{c}5.652 \pm 4.534 \\
(\mathrm{~N}=13)\end{array}$ & $\begin{array}{c}4.445 \pm 3.560 \\
(\mathrm{~N}=10)\end{array}$ & $\begin{array}{c}5.2326 \pm 4.17906 \\
(\mathrm{~N}=23)\end{array}$ & $>0.05$ \\
\hline
\end{tabular}


Table 4. Multivariate logistic regression analysis of retinopathy with variables in the Equation.

\begin{tabular}{cccccccccc}
\hline & B & Begression coefficient & $\begin{array}{c}\text { S.E. } \\
\text { Standard error }\end{array}$ & Wald & $\begin{array}{c}\text { Df } \\
\text { (Degree of freedom) }\end{array}$ & $\begin{array}{c}\text { Sig. } \\
\text { P value }\end{array}$ & $\begin{array}{c}\text { Exp B } \\
\text { (odd ratio) }\end{array}$ & $\begin{array}{c}\text { 95\% C.I. for EXP(B) } \\
\text { Lower }\end{array}$ & Upper \\
\hline Age & 0.012 & 0.049 & 0.060 & 1 & 0.807 & 1.012 & 0.919 & 1.115 \\
HbA1C & 0.118 & 0.353 & 0.112 & 1 & 0.738 & 1.125 & 0.563 & 2.248 \\
TC & 0.014 & 0.012 & 1.479 & 1 & 0.224 & 1.014 & 0.991 & 1.037 \\
BMI & 0.201 & 0.201 & 1.003 & 1 & 0.317 & 1.223 & 0.825 & 1.814 \\
SBP & 0.032 & 0.030 & 1.187 & 1 & 0.276 & 1.033 & 0.974 & 1.095 \\
IL17 & 0.270 & 0.113 & 5.675 & 1 & 0.017 & 1.309 & 1.049 & 1.635 \\
Sr. Creatinine & -1.024 & 0.883 & 1.345 & 1 & 0.246 & 0.359 & 0.064 & 2.027 \\
constant & -20.792 & 9.434 & 4.857 & 1 & 0.028 & 0.000 & &
\end{tabular}

Table 5. Results of multiple logistic regression analysis of neuropathy.

\begin{tabular}{|c|c|c|c|c|c|c|c|c|}
\hline & \multirow{2}{*}{$\begin{array}{c}\text { B } \\
\text { Regression coefficient }\end{array}$} & \multirow{2}{*}{$\begin{array}{c}\text { S.E } \\
\text { Standard error }\end{array}$} & \multirow{2}{*}{ Wald } & \multirow{2}{*}{$\begin{array}{c}\text { Df } \\
\text { Degrees } \\
\text { of freedom }\end{array}$} & \multirow{2}{*}{$\begin{array}{c}\text { Sig. } \\
\text { P value }\end{array}$} & \multirow{2}{*}{$\begin{array}{c}\operatorname{Exp}(\mathrm{B}) \\
\text { Odds ratio }\end{array}$} & \multicolumn{2}{|c|}{$95 \%$ C.I. for $\operatorname{EXP}(B)$} \\
\hline & & & & & & & Lower & Upper \\
\hline Age & -0.052 & 0.063 & 0.685 & 1 & 0.408 & 0.949 & 0.840 & 1.074 \\
\hline Duration & -0.323 & 0.477 & 0.459 & 1 & 0.498 & 0.724 & 0.284 & 1.844 \\
\hline HbA1C & 0.055 & 0.701 & 0.006 & 1 & 0.938 & 1.056 & 0.267 & 4.176 \\
\hline TC & 0.004 & 0.018 & 0.052 & 1 & 0.820 & 1.004 & 0.969 & 1.040 \\
\hline BMI & 0.634 & 0.395 & 2.581 & 1 & 0.108 & 1.886 & 0.870 & 4.089 \\
\hline SBP & -0.074 & 0.060 & 1.514 & 1 & 0.218 & 0.929 & 0.826 & 1.045 \\
\hline IL17 & 0.499 & 0.235 & 4.522 & 1 & 0.033 & 1.647 & 1.040 & 2.608 \\
\hline Sr. Crea & -0.958 & 1.456 & 0.433 & 1 & 0.511 & 0.384 & 0.022 & 6.659 \\
\hline Constant & -17.194 & 14.085 & 1.490 & 1 & 0.222 & 0.000 & & \\
\hline
\end{tabular}

Table 6. Pearson correlation of IL 17 with different parameters.

\begin{tabular}{|c|c|c|c|c|c|c|c|c|c|c|c|c|c|c|}
\hline & & Age & Duration & $\mathrm{HbAlc}$ & TC & TG & $\mathrm{HDL}$ & LDL & VLDL & BMI & SBP & DBP & FBG & $\begin{array}{c}2 \mathrm{Hr} \\
\mathrm{PPBG}\end{array}$ \\
\hline \multirow{3}{*}{ IL17 } & Pearson & & & & & & & & & & & & & \\
\hline & $\begin{array}{l}\text { Correlation } \\
(\mathrm{r})\end{array}$ & 0.196 & $0.579^{* *}$ & $0.551^{* *}$ & $0.289^{* *}$ & $0.342^{* *}$ & $-0.289^{* *}$ & $0.276^{* *}$ & $0.326^{* *}$ & 0.151 & $0.703^{* *}$ & $0.571^{* *}$ & 0.117 & $0.221^{*}$ \\
\hline & $\begin{array}{l}\text { Sig. (2-tailed) } \\
\text { (P value) }\end{array}$ & 0.064 & 0.000 & 0.000 & 0.006 & 0.001 & 0.006 & 0.008 & 0.002 & 0.156 & 0.000 & 0.000 & 0.274 & 0.036 \\
\hline
\end{tabular}

\section{Discussion}

IL-17, which is a pro-inflammatory cytokine has been studied in development of diabetes. In our study, levels of IL 17 (normal level $\leq 10 \mathrm{pg} / \mathrm{ml}$ ) was found to be increased in T2DM (mean $=25.06 \mathrm{pg} / \mathrm{ml}$ ) which is higher than in non-diabetic controls (mean $=5.232 \pm 2.867 \mathrm{pg} / \mathrm{ml}$ ) (Table 3). These findings are consistent with the studies of Chen et al. which showed increase in level of IL-17 in newly diagnosed diabetes than the healthy controls [9]. The level of IL 17 was even more in the group of patients with acute complications (group B) with a mean 
value of $20.386 \mathrm{pg} / \mathrm{ml}$. The level of IL 17 was highest in the group with chronic complications with a mean value of $39.727 \mathrm{pg} / \mathrm{ml}$ as seen in Table 3. This finding is in corroboration with Yousefidaredor et al. who found that IL 17 plays an important role in development of T2DM and its complications via the up regulation of several inflammatory molecules including angiotensin II type I receptor and JAK 2 STAT 3 pathway related molecules [10]. These results indicate IL 17 as a contributory factor to the inflammatory process in T2DM and its complications. However this finding does not corroborate with the findings of Roohi et al. and Vasanthakumar et al. that showed no significant difference in the level of IL 17 between type 2 diabetes mellitus and controls [11] [12].

Naureen et al. have shown that female patients with diabetes and its complications have greater oxidative stress as compared to males of similar age groups. They found higher levels of IL 17 in their female patients [13]. We too found similar results with a higher mean value of IL 17 among our female patients (Table 3) which shows mean value of IL 17 in females as compared to males across all groups (i.e. among .group A, B, C and D).

In multivariate logistic regression analysis it was found that there is positive association of IL 17 with Diabetic Retinopathy with an odds ratio of 1.309 (P = 0.017) (Table 4). Our study is at par with Wang et al. who found that IL 17 is an independent risk factor for non proliferative retinopathy and that IL 17 A levels significantly increased the risk of NPDR (odds ratio $=1.22 ; \mathrm{P}<0.05$ ) [14]. Liu et al. in their study comprising 19 patients with proliferative diabetic retinopathy (PDR) and 20 non diabetic controls found increased IL 17 levels in the sera of patients with PDR as compared to controls. Furthermore, increased expression levels of IL 17 were detected in fibrovascular membranes and in peripheral blood mononuclear cells (PBMC) harvested from patients with PDR [15]. However our results are in disagreement with the results of the study by Nadeem et al. where it was found that IL 17 has a protective role in Diabetic retinopathy [16].

In multivariate logistic regression analysis we found positive association of IL 17 with Diabetic Neuropathy with a significant $P$ value of 0.033 with odds ratio of 1.647 (Table 5). Sandireddy et al. also suggested that IL 17 can sensitize peripheral receptors causing neuropathic pain in patients of diabetic neuropathy [17]. According to Doupis et al., inflammation and microvascular reactivity are needed for development of diabetic neuropathy and suggested that the chronic state of hyperglycemia culminates to oxidative stress which initiates and amplifies neuroinflammation leading to production of proinflammatory cytokines which are responsible for nerve tissue damage and neuropathies [18].

In multi variate regression analysis, nephropathy did not show any significant association with IL $17(\mathrm{P}=0.13)$. A shorter duration of diabetes in patients of Diabetic Nephropathy in our case along with the highly prevalent endemic CKD in our region not due to diabetes explains the failure to attain the significant correlation with nephropathy.

As shown in Table 6, we found positive Pearsons correlation of IL 17 with Systolic blood pressure, diastolic blood pressure, $2 \mathrm{hr}$ post prandial glucose, total 
cholesterol, triglycerides, very low density lipoprotein and low density lipoprotein value. We found a negative correlation with serum high density lipoprotein HDL and IL $17(\mathrm{r}=-0.289)$. Our findings are in corroboration with study by Marwan et al. in patients of T2DM., where hypertension and serum TG was significantly correlated with IL 17 [19]. Kologrivova et al. also observed increased IL 17 in patients with T2 DM and hypertension [20]. Mahmoud et al. in their study suggested that IL 17 was significantly correlated with dyslipidemia [21]. There was a positive correlation between levels of IL 17 and blood HbAlc with a coefficient(r) value of 0.551 indicating that a higher level of IL 17 is indicative of poor glycaemic control. Studies by Dumanovic et al. showed that there is a significant reduction of $\mathrm{HbAlc}$ with decreased IL 17 corroborative with our findings [22]. A small sample size was the primary limitation in this study which was due to financial constraints. A large study with many more variables may shed more light on the relationship between IL-17 and diabetes.

\section{Conclusion}

The present study was undertaken to study the levels of IL 17 in patients with T2DM with and without acute and chronic complications. It was found that IL 17 was significantly high in patients of T2DM without any complications as compared to controls. By multivariate logistic regression analysis IL 17 has been found to be an independent marker of severity of degree of neuropathy and retinopathy. Further levels of IL 17 were positively correlated to hypertension and dyslipidemia. We suggest an inflammatory state in diabetes with or without complications. Thus IL 17 can act as a marker of inflammation and complications in patients of diabetes mellitus. However, multicentric studies with larger number of patients should be undertaken for better association.

\section{Conflicts of Interest}

The authors declare no conflicts of interest regarding the publication of this paper.

\section{References}

[1] Devaraj, S., Dasu, M.R. and Jialal, I. (2010) Diabetes Is a Proinflammatory State: A Translational Perspective. Expert Review of Endocrinology \& Metabolism, 5, 19-28. https://doi.org/10.1586/eem.09.44

[2] Shanmugam, N., Reddy, M.A., Guha, M., et al. (2003) High Glucoseinduced Expression of Proinflammatory Cytokine and Chemokine Genes in Monocytic Cells. Diabetes, 52, 1256-1264. https://doi.org/10.2337/diabetes.52.5.1256

[3] Dandona, P., Aljada, A., Chaudhuri, A., et al. (2005) Metabolic Syndrome. A Comprehensive Perspective Based on Interactions between Obesity, Diabetes and Inflammation. Circulation, 111, 1448-1454. https://doi.org/10.1161/01.CIR.0000158483.13093.9D

[4] Misra, D.P., Das, S. and Sahu, P.K. (2012) Prevalence of Inflammatory Markers (High-Sensitivity C-Reactive Protein, Nuclear Factor-kB, and Adiponectin) in Indian Patients with Type 2 Diabetes Mellitus with and without Macrovascular Com- 
plications. Metabolic Syndrome and Related Disorders, 10, 209-213.

https://doi.org/10.1089/met.2011.0044

[5] Xia, C., et al. (2017) Role of T Lymphocytes in Type 2 Diabetes and Diabetes Associated Inflammation. Journal of Diabetes Research, 2017, Article ID: 6494795. https://doi.org/10.1155/2017/6494795

[6] Yousefidaredor, H., Zare, B., Mohammmad, H., Hamid, A., Shokrollah, B., Vahid, K. and Arababadi, M. (2014) IL-17A Plays an Important Role in Induction of Type 2 Diabetes and Its Complications. Asian Pacific Journal of Tropical Disease, 4, 412-415. https://doi.org/10.1016/S2222-1808(14)60598-3

[7] Takeuchi, M., Sato, T., Sakurai, Y., et al. (2017) Association between Aqueous Humor and Vitreous Fluid Levels of Th17 Cell-Related Cytokines in Patients with Proliferative Diabetic Retinopathy. PLOS ONE, 12, e0178230. https://doi.org/10.1371/journal.pone.0178230

[8] Cortvrindt, C., Speeckaert, R., Moerman, A., Delanghe, J.R. and Speeckaert, M.M. (2017) The Role of Interleukin-17A in the Pathogenesis of Kidney Diseases. $\mathrm{Pa}$ thology, 49, 247-258. https://doi.org/10.1016/j.pathol.2017.01.003

[9] Chen, C., Shao, Y., Wu, X., Huang, C. and Lu, W. (2016) Elevated Interleukin-17 Levels in Patients with Newly Diagnosed Type 2 Diabetes Mellitus. Biochemistry and Physiology, 5, 206. https://doi.org/10.4172/2168-9652.1000206

[10] Yousefidaredor, H., et al. (2014) IL-17A Plays an Important Role in Induction of Type 2 Diabetes and Its Complications. Asian Pacific Journal of Tropical Disease, 4, 412-415. https://doi.org/10.1016/S2222-1808(14)60598-3

[11] Roohi, A., Tabrizi, M., Abbasi, F., et al. (2014) Serum IL-17, IL-23, and TGF- $\beta$ Levels in Type 1 and Type 2 Diabetic Patients and Age-Matched Healthy Controls. BioMed Research International, 2014, Article ID: 718946. https://doi.org/10.1155/2014/718946

[12] Vasanthakumar, R., Mohan, V., Anand, G., Deepa, M., Babu, S. and Aravindhan, V. (2015) Serum IL-9, IL-17, and TGF- $\beta$ Levels in Subjects with Diabetic Kidney Disease (CURES-134). Cytokine, 72, 109-112. https://doi.org/10.1016/j.cyto.2014.10.009

[13] Naureen, F., Syed, M.F., Swaleha, Z., SheeluShafiq, S., Shagufta, M. and Mohammad, O. (2017) Emerging Role of Interleukins IL-23/IL-17 Axis and Biochemical Markers in the Pathogenesis of Type 2 Diabetes: Association with Age and Gender in Human Subjects. International Journal of Biological Macromolecules, 105, 1279-1288. https://doi.org/10.1016/j.ijbiomac.2017.07.155

[14] Wang, C., Wang, L., Liu, J., Song, J., Sun, Y., Lin, P., Liang, K., Liu, F., He, T., Sun, Z., Hou, X. and Chen, L. (2016) Irisin Modulates the Association of Interleukin-17A with the Presence of Non-Proliferative Diabetic Retinopathy in Patients with Type 2 Diabetes. Endocrine, 53, 459-464. https://doi.org/10.1007/s12020-016-0905-X

[15] Liu, S., Lin, Y.U. and Liu, X. (2016) Protective Effects of SIRT1 in Patients with Proliferative Diabetic Retinopathy via the Inhibition of IL-17 Expression. Experimental and Therapeutic Medicine, 11, 257-262. https://doi.org/10.3892/etm.2015.2877

[16] Nadeem, A., Shakeela, Z., Aneela, A., Khursheed, Faheem, S., Abu, Z. and Hanan, A. (2014) Negative Association of Serum IL-6 and IL-17 with Type-II Diabetes Retinopathy. Iranian Journal of Immunology, 11, 40-48.

[17] Sandireddy, R., Ganesh, V., Areti, A., Komirishetty, P. and Kumar, A. (2014) Neuroinflammation and Oxidative Stress in Diabetic Neuropathy: Futuristic Strategies Based on These Targets. International Journal of Endocrinology, 2014, Article ID: 674987. https://doi.org/10.1155/2014/674987 
[18] Doupis, J., Rahangdale, S., Gnardellis, C., Pena, S.E., Malhotra, A. and Veves, A. (2011) Effects of Diabetes and Obesity on Vascular Reactivity, Inflammatory Cytokines, and Growth Factors. Obesity, 19, 729-735. https://doi.org/10.1038/oby.2010.193

[19] Marwan, A.L. (2016) Increased Serum Cytokines Levels in Type 2 Diabetes Mellitus Associated with Arterial Hypertension: A Link to Cardio-Metabolic Risk Factors. Turkish Journal of Endocrinology and Metabolism, 20, 127-131.

https://doi.org/10.4274/tjem.3209

[20] Kologrivova, I.V., Suslova, T.E., Koshel'skaya, O.A., Vinnitskaya, I.V. and Trubacheva, O.A. (2014) System of Matrix Metalloproteinases and Cytokine Secretion in Type 2 Diabetes Mellitus and Impaired Carbohydrate Tolerance Associated with Arterial Hypertension. Bulletin of Experimental Biology and Medicine, 156, 635-638. https://doi.org/10.1007/s10517-014-2413-4

[21] Mahmoud, F. and Al-Ozairi, E. (2013) Inflammatory Cytokines and the Risk of Cardiovascular Complications in Type 2 Diabetes. Disease Markers, 35, 235-241. https://doi.org/10.1155/2013/931915

[22] Dumanovic, M.S., Jeremic, D., Pantovic, A., Janjetovic, K., Pejkovic, D.M., Cvijovic, G., Stevanovic, D., Micic, D. and Trajkovic, V. (2013) Therapeutic Improvement of Glucoregulation in Newly Diagnosed Type 2 Diabetes Patients Is Associated with a Reduction of IL-17 Levels. Immunobiology, 218, 1113-1118.

https://doi.org/10.1016/j.imbio.2013.03.002 